\title{
21. Deciduomal Response to Uterine Trauma Following Placement of Brain Lesions in Gonadotropin-Primed Immature Rats
}

\author{
By Takeo MAchidA*) and Kiyoshi TAKeWAKI**) \\ (Comm. by Yô K. OKADA, M. J. A., Jan. 12, 1971)
}

In immature rats with ovaries mildly luteinized by injections of 5 I.U. PMS and 2 I.U. HCG, uterine traumatization failed to evoke formation of deciduomata (Takewaki, 1969). However, following daily injections of prolactin (Takewaki, 1969), mechanical stimulation of the cervix uteri (Takewaki, 1970a) or a single injection of $50 \mu \mathrm{g}$ reserpine (Takewaki, 1970b), a majority of immature rats so primed developed deciduomata in response to uterine trauma. These findings indicate that the hypothalamo-hypophysial mechanism involved in the control of prolactin secretion like that in adult rats is operating in immature animals.

Furthermore, Takewaki and Machida (1970) reported that, following bilateral placement of electrolytic lesions in the ventromedial posterior region of the hypothalamus, 4 of 9 immature rats bearing ovaries mildly luteinized by similar injections of PMS and HCG showed a positive deciduomal reaction to uterine trauma. Yet, in this experiment, deciduomata were noted only in a low percentage of lesioned rats. This may be accounted for by a low prolactinsecreting capacity of the anterior hypophysis in immature rats, as suggested by both in vitro (Meites, Kahn and Nicoll, 1961) and in vivo experiments (Voogt, Chen and Meites, 1970).

It should be mentioned here, however, that some workers (Flerkó and Bárdos, 1959; Flament-Durand and Desclin, 1964) have suggested that a region dorsolateral to the paraventricular nuclei is concerned with the control of PIF release and consequently of prolactin secretion in the rat. Accordingly, experiments were designed to study the effects of small lesions placed in this region of the brain on corpora lutea induced by PMS-HCG injections in immature rats.

Materials and methods. Immature female rats of the $\mathrm{T}$ strain were used in all experiments. At 21 days of age, rats were weaned and given a single subcutaneous injection of 5 I.U. PMS (Primantron,

*) Zoological Institute, Faculty of Science, University of Tokyo.

**) Endocrinology Laboratory, Kawasaki Medical College, Shōson, Okayama. 
Schering A. G., Berlin), followed 50 hours later by a single subcutaneous injection of 2 I.U. HCG (Primogonyl, Schering A. G., Berlin), each dose being dissolved in $0.1 \mathrm{ml}$ of a $0.9 \% \mathrm{NaCl}$ solution.

Two days after HCG injection, bilateral electrolytic lesions were placed stereotaxically in each rat under ether anesthesia. As in the previous experiments (Takewaki and Machida, 1970), stainless steel electrodes $(0.35 \mathrm{~mm}$ in diameter $)$ insulated with Epoxylite to within $0.8 \mathrm{~mm}$ of the tip were placed according to coordinates based on the rat brain atlas of De Groot (1959) adapted for immature rat brain. The horizontal plane passing the interaural line and upper incisor bar was taken as the horizontal zero plane. In a majority of animals, a $1.5 \mathrm{~mA}$ direct current was delivered through the electrodes for 5 or 10 seconds. The electrode was the anode, the cathode being placed on the skin incision.

Vaginal smears were examined from the day following HCG injection onward. On the 4th day after placement of brain lesions, rats were laparatomized under ether anesthesia and the endometrium of the right uterine horn was scratched throughout the entire length of the horn by the method described previously (Takewaki, 1969; 1970a). Vaginal smears were taken for 3 days longer.

Rats were weighed and sacrificed 4 days after uterine traumatization and traumatized horns were checked for gross evidence of deciduomata. The number of corpora lutea in each ovary was noted. Ovaries and traumatized and intact uterine horns were removed from each animal, freed from extraneous tissues, weighed, fixed in Bouin's solution and processed for histological study. Brains were also fixed in Bouin's solution and cut into serial sections at $10 \mu$. Every 10th section was mounted and stained with thionin for examination of brain lesions.

The animals were housed in a temperature-controlled room and had free access to food and water. The lighting schedule provided $14 \mathrm{hr}$ of illumination followed by $10 \mathrm{hr}$ of darkness.

Additional details on experimental designs and procedures are described in the text.

Results. In the first series of experiments, deciduomata were developed in 10 of 21 lesioned rats. Of the 10 rats, in 3 the current was passed for 10 seconds, while in the other 7 for 5 seconds. Deciduomata varied considerably in size among different individuals (Figs. 1, 2). The weights of the uterine horns bearing deciduomata and the contralateral intact horns averaged $111.6 \pm 17.1 \mathrm{mg}$ and $37.8 \pm 2.8 \mathrm{mg}$, respectively. Four of the 10 rats showed only localized deciduomal reaction (Fig. 2). The ovaries of the 10 rats weighed $32.7 \pm 3.9 \mathrm{mg}$ on an average, containing 8-15 corpora lutea per animal. 


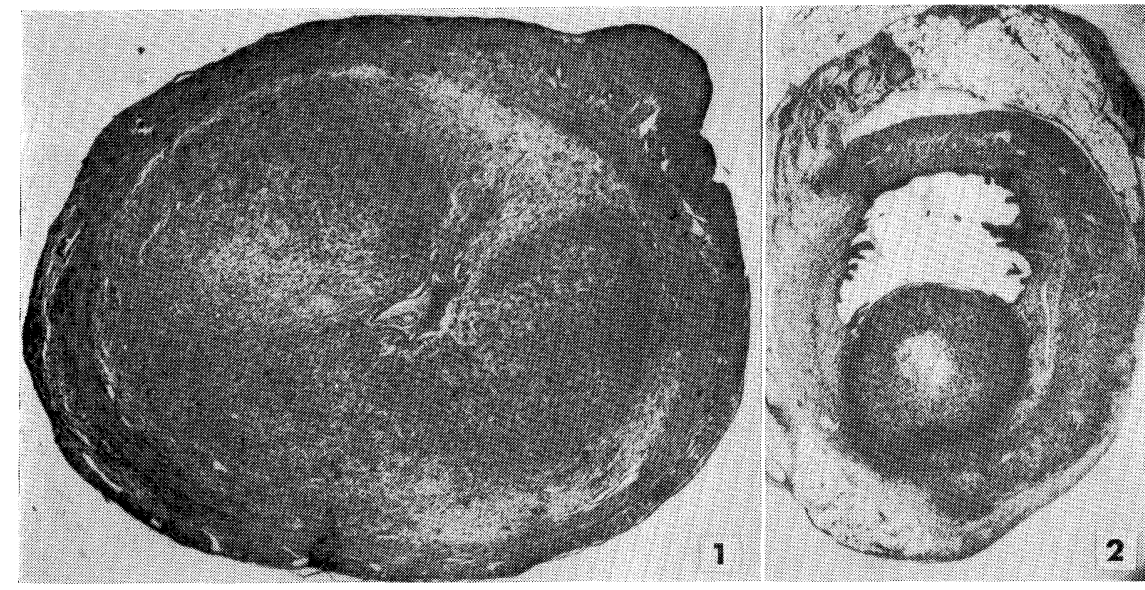

Fig. 1. Uterus with deciduoma of an immature rat having ovaries luteinized by PMS-HCG treatment. In this animal, bilateral lesions were placed in a region dorsolateral and a little anterior to the paraventricular nuclei. $\times 20$

Fig. 2. Uterus with localized nodular deciduoma of a rat similarly treated and similarly lesioned. $\times 20$

In all the rats showing a positive deciduomal reaction, histological studies of the brains revealed that a region dorsolateral and a little anterior to the paraventricular nuclei, i.e. an area between the stria medullaris thalami and the fornix or around the nucleus proprius stria terminalis, was damaged (Fig. 3), while in the 11 rats which failed to form deciduomata, brain lesions which had been placed by sending a $1.5 \mathrm{~mA}$ direct current for 10 (7 cases) or 5 seconds (4 cases) were located more anteriorly, the nucleus proprius commissurae anterioris, preoptic area, nucleus proprius striae terminalis, fornix or the area anterior hypothalami being more or less destructed. In the 11 animals, ovaries weighed $42.2 \pm 5.8 \mathrm{mg}$, the traumatized and intact uterine horns being $58.5 \pm 21.6 \mathrm{mg}$ and $39.8 \pm 15.0 \mathrm{mg}$, respectively. Twelve other rats (Series 2) carrying lesions situated more caudally on the outside of the nucleus reuniens thalami or between the nucleus reuniens thalami and the zona incerta, also failed to react to uterine trauma by formation of deciduomata. These 12 rats received the current for 5 seconds. The mean weights of ovaries, traumatized horns and intact horns were $22.9 \pm 4.4 \mathrm{mg}$, $39.3 \pm 12.4 \mathrm{mg}$ and $27.3 \pm 8.8 \mathrm{mg}$, respectively.

If a $1.5 \mathrm{~mA}$ direct current was applied for 2 seconds instead of 5 or 10 seconds, lesions placed in the effective area dorsolateral and a little anterior to the paraventricular nuclei were incapable of rendering the animals to form deciduomata in response to uterine trauma ( 2 cases). Insertion of the electrodes without sending the 
[Vol. 47,

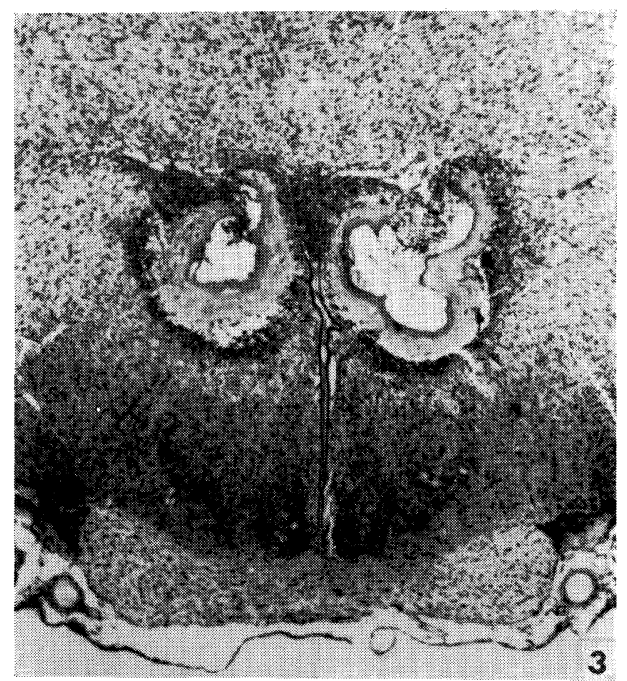

Fig. 3. Typical bilateral electrolytic lesions dorsolateral and a little anterior to the paraventricular nuclei. $\quad \times 10$

current was also without effect (3 cases).

In those animals which showed a positive deciduomal reaction, vaginal smears were continuously of the diestrous type from the day of placement of the brain lesions until the day of sacrifice, frequently containing copious mucus. By contrast, in 10 of the 28 rats in which no deciduomata were elicited vaginal smears were cornified for one or a few days after brain lesions had been placed.

Discussion. Evidence for the luteotropic action of prolactin appears to be unequivocal in the rat (Meites and Nicoll, 1966). Accordingly, the present experiments on immature rats with ovaries mildly luteinized by priming with 5 I.U. PMS and 2 I.U. HCG seem to indicate that a region dorsolateral and a little anterior to the paraventricular nuclei is concerned with the control of PIF release, since only those animals bearing bilateral lesions in this area developed deciduomata in response to uterine trauma. If lesions were placed a little more anteriorly or posteriorly, no deciduomata were elicited.

However, Takewaki and Machida (1970) reported that following bilateral placement of electrolytic lesions in the ventromedial posterior region of the hypothalamus, some immature rats similarly primed formed deciduomata in reaction to uterine trauma. Further studies are necessary to determine the possible relation between these two kinds of lesions in stimulating the secretion of prolactin from the anterior hypophysis.

Although the data so far secured are still meager, bilateral 
brain lesions resulted from a $1.5 \mathrm{~mA}$ direct current delivered through the electrodes for 2 seconds were incapable of causing the secretion of prolactin in amounts sufficient to activate corpora lutea, even if they were placed in a region dorso-lateral and a little anterior to the paraventricular nuclei. This may be accounted for by assuming that the lesions were too small to destroy completely the neural structures responsible for the control of PIF release.

In those rats which failed to elicit deciduomata in response to uterine trauma, vaginal estrus took place not infrequently after placement of brain lesions. It appears likely that in such animals the brain lesions disturbed the normal pattern of secretion of gonadotropins, bringing about hormonic conditions incapable of supporting the development and maintenance of deciduomata.

Summary. In immature rats with ovaries mildly luteinized by injections of 5 I.U. PMS and 2 I.U. HCG, bilateral brain lesions were placed stereotaxically by applying a $1.5 \mathrm{~mA}$ direct current through stainless steel electrodes for 5 or 10 seconds. Following uterine traumatization carried out 4 days later, deciduomata were developed only in animals in which a region dorsolateral and a little anterior to the right and left paraventricular nuclei was destructed. Those rats bearing lesions situated more anteriorly or posteriorly were incapable of responding to uterine trauma by formation of deciduomata. Accordingly, the above-mentioned region of the brain appears to be concerned with the control of PIF release and consequently of hypophysial prolactin secretion.

\section{References}

De Groot, J. (1959): Verhandel. Koninkl. Nederl. Akad. Wetensch., afd. Natuurk., Ser. 2, 52(4), 1.

Flament-Durand, J., and L. Desclin (1964): Endocrinology, 75, 22.

Flerkó, B., and V. Bárdos (1959): Acta Neuroveg., 20, 248.

Meites, J., and C. S. Nicoll (1966): Ann. Rev. Physiol., 28, 57.

Meites, J., R. H. Kahn, and C. S. Nicoll (1961) : Proc. Soc. Exp. Biol. Med., 108, 440.

Takewaki, K. (1969): Annot. Zool. Japon., 42, 126.

(1970a): Sci. Rep. Tokyo Woman's Christian Coll., Nos. 12-14, 175. (1970b): Proc. Japan Acad., 46, 552.

Takewaki, K., and T. Machida (1970): Annot. Zool. Japon., 43, 23.

Voogt, J. L., C. L. Chen, and J. Meites (1970): Am. J. Physiol., 218, 396. 